\title{
Propitious time in Entrepreneurship
}

\author{
David Leong \\ University of Canberra, University of Canberra, Bruce ACT 2617 Australia \\ Email address: u3221961@uni.canberra.edu.au
}

Key words: Entrepreneurship, time, luck, risks and uncertainties

\begin{abstract}
Time is not invariant in the entrepreneurial journey. Timing is everything in entrepreneurial venturing. This paper shifts the inquiry of entrepreneurship from micro (traits, characteristics and behaviour) and macro (environmental context) perspective and the multi-level approaches from discovery, creation to co-creation (Garud et al., 2014) to a study of the relevance of time in the entrepreneurial pathway development. The context of luck or exogenous change or external or internal perturbation that may lead to the propitious time to act will be examined with reference to research conducted by Peter R. Darke (Darke \& Freedman, 1997). It needs contextualization to fit the entrepreneurial paradigm on the propitious time to enact (Weick \& Karl E, 1995) which is the main conceptualization in this paper. The concept of convergence, in a particular spatial-temporal (space-time), between the opportunity and the entrepreneur, is the core of this study and this paper will focus specifically on the extent and nature of this convergence in relation to time. Propitious time to trigger actions when opportunities surface or avoidance when the scale of risks are too large to bear- this study of when to act is therefore central to the theory of entrepreneurship.
\end{abstract}

\section{PERSPECTIVE OF TIME}

Temporal dynamics is at the core of entrepreneurship. Time, in the sense of measured interval, usually denoted by " $t$ " occurs and appears in many scientific and mathematical formulas. Time, as we experience it, in its linearity, incessantly becoming, with its irreversibility and its distinctiveness in the past, present and the future (Griffin \& David Ray, 1986) plays a critical role in entrepreneurship. With linearity and the arrow of time in a one-directional motion, the entrepreneurs experience the explicate orders. This happens because, just as the implicate order unfolds to give rise to the explicate reality over time, our mind enfolds the explicate order back into the implicate order of conscious memory (Bohm, 1973). Bohm uses the perception of music and melody as an illustration. On hearing each note, hearing is not experienced in isolation but in terms of the context of all the notes that have come before it in the composition. As each new note is heard, it is enfolded into the ongoing consciousness of the music, building up a mental structure which creates expectations reaching forward into the future in the hope to reach a crescendo. The implicate order drives the reverse of this process: each moment of explicate reality is enfolded within the implicate order, becoming manifest as it is unfolded (Bohm, 1973). The rolling forward and unfolding in the explicate reality is at the same time enfolded within the implicate order (rolling backward through introspection), becoming manifested as it unfolds. The "rolling forward-rolling-backwards" vacillation shapes actions through adaptation. Entrepreneurial actions, are continuously developing, are enfolded in the implicate order (through past and prior actions and experience) and then to unfold into the explicate reality. In this paper, inquiry into the question of time and the emergence of actions in entrepreneurship and the adaptation of the actions to accommodate the shifted contexts in the sociomaterial network. The heterogeneity of the entrepreneurial socio-material network plays a crucial part in the behaviour of the entrepreneurs as it provides the contexts for adaptative changes with obstacles or the lack of resources. Entrepreneurs manage the pathway development as they move along the time continuum. The cumulative capacities, including experience and prior actions of the entrepreneurs become a structuring force of the network by feeding the entrepreneurial process. The task of the entrepreneuring process is then taken to accommodate new observations, of internal and external resources, networks and external helps, by means of adaptations within the ecosystem, so as to fit the new facts and to adapt over time. Summarily, the actions undertaken by entrepreneurs in the socio-material network involves two complementary movements over time along the entrepreneurial pathway - accommodation and assimilation (Bohm, 1973). Where accommodation is taken to mean fitting, cutting to a pattern, adapting, imitating and conforming to new situation, assimilation is taken to mean digest and "to-take-into", the two complementary movements along the entrepreneurial pathway and process are part of the "rolling forward-rolling-backwards" to create new reality over time.

The enfolding or implicate order (rolling backward) to the explicate order (rolling forward) action mould the time experience and is best encapsulated by (Bohm, 1973) where he inquired into the question of emergence of new orders in physics. His theorization of the state of emergence is useful in the conceptualization of emergence of time from a present state to the future state. "One of the most striking examples of the implicate order is to be seen by considering the function of 
the hologram which clearly reveals how a total content (in principle extending over the whole of space and time) is "enfolded" in the movement of waves (electromagnetic and other kinds) in any given region. We then come to the notion that the quantum theory indicates that this implicate order is not merely a dependent or fortuitous feature of the content, but rather, that it should be considered as the independent ground of existence of things, while the ordinary explicate order is what should be considered as dependent."(Bohm, 1973). The perspective of time has a certain orderliness - moving unidirectionally and irreversibly in a forward direction and as it moves, always creates a past with a present "now" and an unfolding future. A general feature of such time-development in the 3 phases (past, present and future) has certain basic notion of order as permanent, unchangeable and irreversible. Where entrepreneurial venturing is concerned in this respect is the task of accommodating new observations of externalities including the recognition of opportunities in the present and by means of adaptations within these basic notions of order of past, present and future so as to fit new facts in the current observed reality and then to craft the next step into the future. It may thus be inferred that entrepreneurial adaptation (Messier \& Puettmann, 2011), assimilation and accommodation of new facts and observations within the "present state" is the main activity and concern of the entrepreneurs and then to decide on the shape of things to come which can have many possibilities. To assimilate and to accommodate known orders of thoughts and experiences from the past and in the act of assimilation of new facts and information, including discovery of new opportunities to roll forward into the future is an exercise of entrepreneurial venturing. In order to understand what is the proper role of accommodation and assimilation of facts within the environmental contexts or ecosystem (Kuckertz, 2019), it is important to note that facts or even opportunities as perceived by entrepreneurs (Dimov, 2011) may not be independent existential object as they may be figment or imagination in the minds of the entrepreneurs and exist as artefact described by Simon Herbert in the "The Sciences of the Artificial" (Warner \& Simon, 1969) (Sarasvathy, 2003). Thus in a certain sense, entrepreneurs "make" the fact as they understand them or summarily, with the immediate observation of the actual situation, entrepreneurs ascribe meanings - or sensemaking (Weick et al., 2005) and develop the fact by providing order, form and structure with the aids of their existing knowledge and experiences. It is this constant "rolling-backing-rolling-forward" iterations with perception, discovery, creation and cocreation (Garud et al., 2014) by the entrepreneurs that should properly be interwoven continually with the present "now" activities; coupled with accommodation and assimilation of the past knowledge and experience into giving shape of what is to come in the future, forging a new conceptual understanding and notion of order of time in entrepreneurship.

Entrepreneurship is a multi-faceted phenomenon that cuts through many disciplines of studies and under the rubric of entrepreneurship there are many units of analysis, theoretical perspectives and methodologies to give bound and conceptualized framework of entrepreneurship. Entrepreneurship connotes a dynamic of movement and activities across time (Bird \& West, 1998). Time enters into entrepreneurial equation at all points involving organization process, of social and material resources. Past experience and understandings of the past form a backdrop for the present "now" such that any actions thereon are taken leading to a future on the venturing process (Bird \& West, 1998). The study of entrepreneurship must therefore necessarily include the temporal dimension of time. Schumpeter defined entrepreneurship as "carrying out new combinations" (Schumpeter, 1934) and it has to be done over time. Knight focused on risks and uncertainties and also on the ability to predict the future (Knight, 1921)- which is a necessary temporal dimension which also mean that the prediction is predicating on propitious time to act on the prediction. Prediction without acting or enactment (Jack et al., 2008) on the prediction is as good as no prediction. Kirzner's advocacy is on the arbitrage and the ability to anticipate the next market imperfections and imbalances (Kirzner, 1973). Arbitraging and betting the future on the discrepancies of the market imperfection predicate on propitious time to act and to bet on the correct perceived trends at the correct time. Betting on the wrong or inopportune time is therefore not a convergence event that brings about positive outcomes. Gartner defined entrepreneurship as the creation of new organizations (Gartner, 1988). Time is of essence (Bankoff, 2004). Events such as propitious time shows how timing of events lead to understanding on how the sense of power or self-efficacy operative in the entrepreneurial process is set within temporal parameters (Bankoff, 2004). Entrepreneur is in a dynamic environment and its historicity, marked by the entrepreneurial events resulting from the underlying entrepreneurial processes in time. The importance of time, whether its propitious time or acting in an inopportune time, time is a crucial factor in determining the outcome at every turn of the venture. This explains the nonlinearity of entrepreneurial process Time is of essence is a common everyday phrase, yet in entrepreneurship, this statement has far greater implications insofar as time or timing is a crucial factor for the successful development of the venture pathway, extension of the play and most importantly survival of the venture. The venture historicity will be marked by many external exogenous shocks (Shepherd et al., 2000), triggers and stressors (Heckmann et al., 2010) (collectively, shocks, triggers and stressors shall be collectively known as "perturbations"). The perils in perturbations affect the mortality risk of ventures. In this paper, we argue that in order to make progress to understand the venturing process with respect to the timing of actions in relations to these perturbations in those entrepreneurial events that will shape the probity of success and survival of the ventures. The effects of such perturbations change the behaviours of the entrepreneurs and hence forth the pathway development will change according to the actions that follow in the responses to these perturbations in the entrepreneurial process. The presence of these perturbations are not predictable and are constant in the real world (Heckmann et al., 2010). Ventures will be subject to these inconsistent and unpredictable exposure to such external impacts during the different stage of their venturing process. The point in time at which a perturbation occurs is thus of concern. This allows for the explanation of the evolutionary venturing pathways, path of mortality, novelty and risks. In (Shepherd et al., 2000) the authors propose "that there is a "strategic" mortality risk path that reflects the impact of positive and negative shocks (shocks are exogenous events that alter the overall degree of novelty at a point in time- positive shocks decrease overall novelty, while negative shocks increase overall novelty) and reversals (endogenous actions that increase the overall novelty of the new venture at a point in time) on the mortality risk of a new 
venture. If the incidence and effects of these disruptions can be managed, then venture managers may be able to mitigate the mortality risk for their venture." The authors further argue that "risk reduction strategies can be employed, most of which impact on one or more of the dimensions of mortality risk in order to increase the firm's chances of survival".

Next, this paper will design a framework for integrating the historicity, including a series of risk reduction strategies that impact on the determinants of mortality risk, in terms of accrued experiences from the past to the future at the nexus. See Diagram 1, where the particular moment represents the nexus, the intersection between the past to the future. This framework predicates on how historical assumptions play a formative role in operationalizing time and contexts in entrepreneurial venturing. We then, shall venture into exploring how the variations in the treatment of time and contexts shape entrepreneurial opportunities, actions and the process of change.

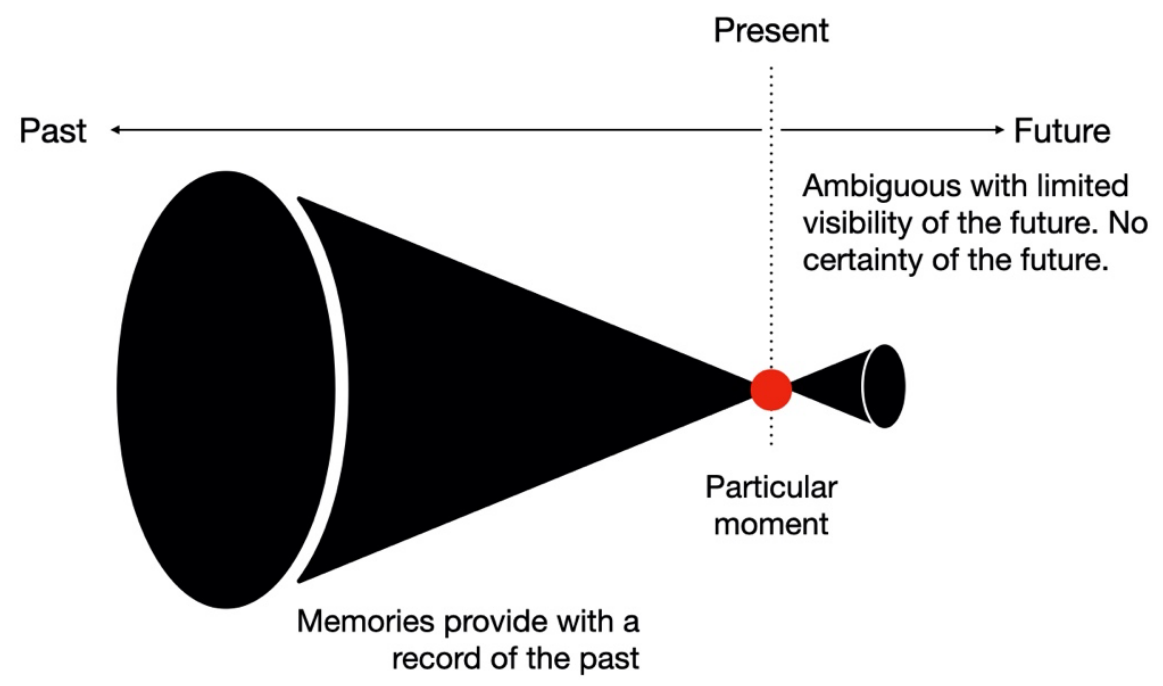

Diagram 1, distinction between the past, present and future.

Memories provides us with the records of the past, of experiences and prior actions and we have no certain knowledge of the future, in fact no certainty at all and when the events are interpreted according to the arrow of time, intuitively, the view of the future is that it is extended in space, unfolding in time in a four dimensional continuum extended in both space and time (Dace, 2018). In entrepreneurial venturing, the "present"- a particular moment- is assigned significance since it is at the "particular moment" that actions are taken that can change the course of trajectory and the mortality risks in the entrepreneurial pathway, by transforming potentiality into actuality or by taking no action and letting the curve flatlines with no activities.

\section{PERCEPTION, ANTICIPATION AND ACTION}

Entrepreneurship connotes a dynamic of motions and movements across time and these motions lead to entrepreneurial pathway extension, sometime with shifts and changes of courses. Temporality of these events from plateauing, transitioning of pathways, extension, punctuated shifts, abrupt stops and restarts which characterize the entrepreneurial process marks the milestones in the journey. Past experience and understanding of the past are enfolded into the present and form a backdrop against which present actions will lead to the indeterminate future for wealth creation (Bird \& West, 1998). Prior to perception at the particular moment (in a specific spatial-temporal dimension), such enfolding of the past to the present is crucial in the decision making for the future. As "lived experience" from the past, entrepreneurship represents a cumulative series of interdependent events that took place from the past, of prior experience that will take root in the present (and carries with it affection and emotions) and affect the decisions for the future and the temporal performance at the nexus (as depicted in Diagram 1 as "particular moment") will determine the future path development. There are mortality risks as the venture progresses over time and how such risks can be mitigated and reduced is established by (Shepherd et al., 2000). The authors establish a definition of mortality risk and argue that "the liability of newness is largely dependent on the degree of novelty (ignorance) associated with a new venture. Novelty is viewed in three different dimensions, viz.: to the market, to the technology of production and to management. Novelty to the market concerns the degree to which the customers are uncertain about the new venture. Novelty in production concerns the extent to which the production technology used by the new venture is similar to the technologies in which the production team has experience and knowledge. Novelty to management concerns the entrepreneurial team's lack of business skills, industry specific information and start-up experience." The authors further argue that mortality risk increases with the degree of novelty in each dimension and with the number of dimensions in which the new venture is novel (Shepherd et al., 2000). Hence, the experiential reservoir of past memories and prior experiences together with the envisioning of the future, with mortality risks and consideration of the external perturbations. An experiential perspective from prior actions focuses the entrepreneur to streams of salient events that were relevant to the 
current undertaking and triggers emergent of the event. A series of significant events accrues, each contributing to the entrepreneur's experiential reservoir and ongoing decision making (Morris et al., 2012).

A model and a set of propositions are presented linking pre-venture experience, experiential processing and anticipated future. A typology of the different permuted experience-anticipation pairs provides a clearer depiction and description of entrepreneur from non-entrepreneur.

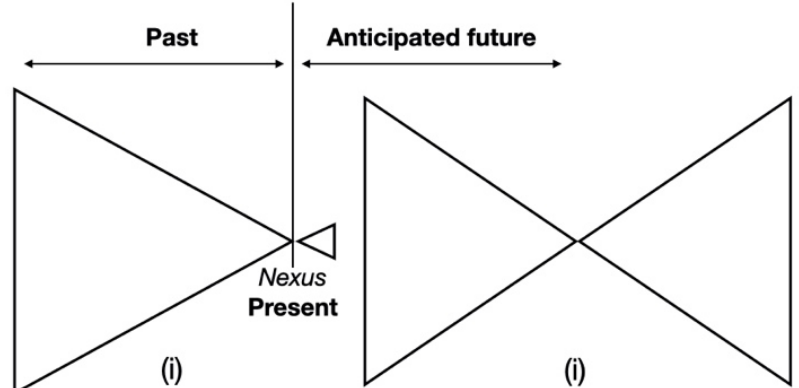

High in experience, low in anticipation (Firm hand)
High in experience, high in anticipation

(Ambitious)

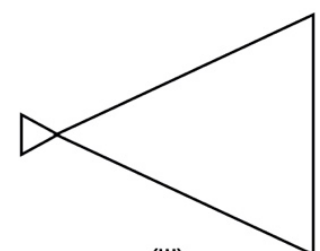

(iii)

Low in experience, high in anticipation

(Cowboy)<smiles>C1CC12CC2</smiles>

(iv) (v)

Low in experience, low in anticipation (Unambitious)
No memory of past, No anticipation of future (Flatliner)

Diagram 2, Typology of experience-anticipation pairs

\begin{tabular}{|c|c|c|c|c|}
\hline Firm hand & Ambitious & Cowboy & Unambitious & Flatliner \\
\hline $\begin{array}{c}\text { High in experience, low in } \\
\text { anticipation }\end{array}$ & $\begin{array}{l}\text { High in experience, high in } \\
\text { anticipation. }\end{array}$ & $\begin{array}{l}\text { Low in experience, high in } \\
\text { anticipation }\end{array}$ & $\begin{array}{l}\text { Low in experience, } \\
\text { low in anticipation }\end{array}$ & $\begin{array}{l}\text { No memory of past, no } \\
\text { anticipation of future }\end{array}$ \\
\hline $\begin{array}{l}\text { The "firm hand" has high } \\
\text { prior relevant experience } \\
\text { but despite these } \\
\text { experiences, anticipation of } \\
\text { outcomes is low. They tend } \\
\text { to be cautious, persistent } \\
\text { with high drive and } \\
\text { determined. They are likely } \\
\text { to be purposive, perceptive, } \\
\text { decisive but risk-averse. } \\
\text { Mostly in managerial } \\
\text { capacities }\end{array}$ & $\begin{array}{l}\text { This category of } \\
\text { entrepreneurs is likely to } \\
\text { be aggressive serial } \\
\text { entrepreneurs and are } \\
\text { ambitious with high } \\
\text { anticipation of what is to } \\
\text { come. Risk-takers. They } \\
\text { dream and have high } \\
\text { anticipation and } \\
\text { expectations and feel that } \\
\text { they have a stronger locus } \\
\text { of control. They are likely } \\
\text { to be transformative to } \\
\text { interact with the socio- } \\
\text { material networks in the } \\
\text { environment to create and } \\
\text { to produce something } \\
\text { novel and disruptive. } \\
\text { Visionary with foresight. }\end{array}$ & $\begin{array}{l}\text { This category of } \\
\text { entrepreneurs are the risk- } \\
\text { takers who may have little } \\
\text { experience but have high } \\
\text { hopes and anticipation and } \\
\text { dream of things bigger than } \\
\text { themselves. Opportunistic, } \\
\text { adventurous and visionary. } \\
\text { Risk-loving. Hustler. }\end{array}$ & $\begin{array}{l}\text { This is likely the "non- } \\
\text { entrepreneurs" category } \\
\text { with no experience nor } \\
\text { with interest to create a } \\
\text { future with high } \\
\text { anticipation and } \\
\text { expectations. Or nascent/ } \\
\text { novice entrepreneur. }\end{array}$ & $\begin{array}{l}\text { This is a category of non- } \\
\text { entrepreneurs who have no } \\
\text { aspirations or vision of a } \\
\text { greater future and live their } \\
\text { existence on "come-what- } \\
\text { may". }\end{array}$ \\
\hline
\end{tabular}

Their characteristics and competencies are derived from their personal histories, experiences and their prior actions and with that enfolded into the present - including temporal orientation and future time perspective, recognition of emerging opportunities, perception of emerging stage problems and phase development issues, and their intentions and anticipation for the future - these are critical variables that enter into the formula for their entrepreneurial journey (Bird \& West, 1998). Anticipation of the future state (Nutt \& R., 1997) provides directionality and to direct their force to the intentionality and entrepreneurial actions. Entrepreneurship is a forward looking activity pushing the boundaries of the possible and impossible that embodies implicit imaginaries over time. With the envisioning of a future, as seen in Diagram 2 with the typology of various anticipation of future states, the spirit of enterprise and entrepreneurial energy (Leong, 2020)(Leong, 2021) will fluctuate according to its energization and its forward discovery (Kirzner, 1997), creation, co-creation (Pitelis, 2012) momentum. These three approaches to studying opportunities that emerge in the entrepreneurship literature discuss about the activity with no reference to time. The specificity of time and the timing of actions are crucial determinants in the entrepreneurial process. This paper shows that the first of these approaches-which focuses on how alert entrepreneurs discover objective opportunities formed by exogenous shocks in an existing market-adopts a critical realist perspective and it has to be seen against the dimension of time; acting in propitious time. The second approach-which focuses on opportunities that are endogenously enacted by the actions of entrepreneurs themselves and do not have an existence independent of those human actions-adopts an evolutionary realist perspective through creation and co-creation. The 
independent human volition acting in propitious time can change the course of the future. Differences between these epistemological assumptions with reference to specificity of time have an important impact on opportunity research in the field of entrepreneurship (Alvarez \& Barney, 2010). On closer scrutiny, reveals that entrepreneurs are continuously making decisions, over time, in the highly uncertain environments and the venture's internal structures (continuous external and internal calibration and alignment) that in turn shape its performance outcomes. Entrepreneurs learn from past choices about how to perform better in the future and such learning can facilitate adaptation and thereafter apply creativity to change and to co-create a new future.

Entrepreneurship creates future value through creative destruction (Schumpeter, 1934); with varying degrees of risks and in uncertain contexts (Knight, 1921) and with 'alertness' to opportunity (Israel M. Kirzner, 1999) (Ardichvili et al., 2003). Entrepreneurial venturing embraces anticipation motivated by a certain aspiration driven by a strong intentionality (Valliere, 2015). The aspiration and strong intentionality are adequate reasons to push the entrepreneurs, over time, to progress into their envisioned future. With entrepreneurial effectuation (Sarasvathy, 2001), the entrepreneurs are concerned with the controllable aspects of an unpredictable future or they can be experimenting with local resources and whatever that is available to co-create the future. A structuration view suggests that the entrepreneur and the social system co-evolve and co-create in the process (Sarason et al., 2006). Entrepreneurial venturing is a process, in time, and is expressed in action through passions (Cardon \& Kirk, 2015). Entrepreneurial venturing is nonlinear transformation and relational. Coupled with other actors in the larger environment along the journey generating a sense of shared anticipation creating the different future states, in Diagram 2, which involves sensing the present and anticipation of the future with experiences of the past. Anticipation is an envisioning of the future state, the effectiveness of anticipation can be improved through greater awareness of the present and the past. The study of the dynamics of emergence and the transitioning in the venture pathway require anticipations of multiple forms, scale and value. Hence, entrepreneurship from an anticipatory standpoint brings more to the fore, the present and the past to be unfolded into the future through anticipation. The anticipatory capacity of the entrepreneurs therefore produce the different types of entrepreneurs from "Ambitious" to "Cowboy". To enfold the past into the present and to develop a deeper insight into the nature of entrepreneurial experience and prior actions, these past events and affective and emotive elements associated with these experiences will influence decision on the present decisionmaking into the future. These events are subject to experiential processing resulting in affective reactions and social learning for the entrepreneurs in the path creation and development taking into consideration risks - to act or not to act. When to act becomes critical for the survival of the venture. Propitious time to act in entrepreneurship matters insofar as survival and success of the venture are concerned. It is to be emphasized here that such perception of time or timing in action should be properly considered in venturing process and be interwoven continually with entrepreneurial activities through accommodation and assimilation knowing full well that the entrepreneurial process is holistic and dynamics and involves many antecedent variables (Bygrave, 1993). Entrepreneurial events that occur along the time line of the process happen because of the change of state - perturbation due to stressors, triggers and external shocks. Every venture pathway developed with different executions and responses to the perturbation and the perception of opportunities is therefore unique.

The element of process has always been present in the social scientist's view of disasters (Bankoff, 2004) or in this entrepreneurial study, opportunities discovery and enactment. At which point in the process is a good time to act? When is the propitious time to act? This directly addresses the question of time in relation to events that can be opportune or disastrous, not simply as an implied dimension in which processes occur nor as marking the period in which such events take place, but rather as a primary unit of analysis that act to either augment or diminish risk. This approach has an ecological perspective that focuses on the effectiveness of entrepreneurial adaptation to its total environment. Culture and social organization are affected by people's experience of their environment but equally the environment is deeply shaped by its histories. The actions of the entrepreneurs, situated in both the material and social network and intersection, are a result of adaptation and assimilation over time. The creation and co-creation of the future state in every journey is unique.

\section{TIME, COMPLEXITY AND TRANSITIONS}

The relationships between time, complexity, and transitions, in the context of new ventures or stable ventures, have been forced into radical change as a consequence of environmental conditions. This model treats time as an unrelenting driving force that requires venture pathway changes and adaptations as part of evolution. Key parameters affecting transitions of ventures owing to the complexity of externalities are explored, as are the rates at which these changes are accomplished basing on entrepreneurial actions over time. The subject of inquiry in this entrepreneurial study is to begin by studying the journey in a process-oriented approach by initiating a dialogue about the nature of the journey, its phases, events and episodes, where it begins and where it ends. With innovativeness and creativity emerging to create a fresh pathway, all these developments in their complexities and transitions occur over time. Entrepreneurship is a process over time but the pathways can be many depending on the specific actions taken. Time seems to be conspicuously absent from empirical entrepreneurial studies where they are framed in a single point in time, like in the study of traits of entrepreneurs (Gartner, 1988) or when it addresses only the discovery of opportunities (Shane, 2003), creation of opportunities (Chiles et al., 2007) where it is seen as singular episode, not from a holistic journey or process perspective. 
The entrepreneurial process is a dynamic, discontinuous change of state and involves numerous antecedent variables. It is highly sensitive to initial conditions. Most importantly and core to this journey is the actor/ entrepreneur and the entire entrepreneurial process must be initiated by the volition of that actor through conscious human actions (Mises, 1949) over time. With human actions there is an essential non-algorithmic aspect to these actions and are closely associated with chaos (Bygrave, 1993). Chaos provide an alluring representation of the entrepreneuring venture process and Bygrave has succinctly said that under some conditions, there are some wild chaotic behaviours that give the observer the feel of entrepreneurship. He adds that it is no more than a mathematical metaphor because its accuracy of the measurements that are needed to observe true scientific chaos in the entrepreneurial process are unattainable in practice (Bygrave, 1993). To understand, in context of the journey along the dimension of time, working definitions of entrepreneurial process and entrepreneurial event shall be used and the better definitions come from (Bygrave \& Hofer, 1992):

\section{- Entrepreneurial process involves all functions, activities and actions associated with perceiving opportunities and the creation of organizations to pursue them. \\ - Entrepreneurial event involves the creation of new organization to pursue an opportunity.}

Entrepreneurs can remake and transform structures within the entrepreneurial ecosystem , contesting norms, shifting positionings and creating new space and pathways by structural mechanisms- including mobilizing of resources, reorganizing and recombining new resources and yoking through attaching, pairing, joining to form new entities (Goddard, 2009). To further add, entrepreneurial events, in this paper will include emergent start, emergent event, venture transitioning, sporadic shifts, punctuated shifts, punctuated emergence, triggers, termination. Each of these terminologies describe actions and activities that occur along the process/ journey.

Emergent event is highly uncertain. Emergent theme arises from the perception of opportunity and the enactment on that opportunity set and is triggered by significant, discontinuous events at the start of the entrepreneurial journey (Cope, 2003). Venture transitioning is describing the motion of the entrepreneur along the time dimension defined as exploration for future sources of competitive advantage, combined with exploitation of current sources of competitive advantages (Ireland \& Webb, 2009) and the actions of discovery, exploration and exploitation define the transitioning along the time dimension. Sporadic shifts are the uncertain movement and directional change that are undertaken informed by changes of existing contexts in the environment. Punctuated emergence in entrepreneurial process arises from a shift in strategic organization (Lichtenstein et al., 2006) as a result of changed environmental conditions and the shift is a departure from the original intent and intended pathway. Triggers affect entrepreneurial actions and are usually exogenous shocks but can sometime be endogenous, that lead to a shift in decision on the pathway development highlighting elements of turbulence, change and unpredictability (Russell \& Faulkner, 2004). The characteristics of entrepreneurial events as described by (Bygrave, 1993) are as follows:

- It is initiated by an act of human volition;

- It is at the level of the individual firm;

- It is a change of state;

- It is a discontinuity;

- It is a holistic process;

- It is a dynamic process

- It involves numerous antecedent variables;

- Its outcomes are extremely sensitive to initial conditions;

- It is unique.

These characteristics and the specifications of the entrepreneurial events as propounded by Bygrave put the whole entrepreneurial process marked by events along the dimension of time as chaotic with Heinsberg's uncertainties. Such indeterminism in the chaos is properly described by (Khalil, 1997) that reality does not consist of physical entities each occupying a certain location and characterized with certain traits. The entities acquire traits and behave differently as a result of further interaction with other entities but these interactions have to be seen from the perspective of time. Different interactions at different points in time may produce different outcomes. In (Bohm \& Fowler, 1978), the concept of potentiality is expressed. For Bohm, matter moves constantly from the realm of abstract space, in this case within the space of the entrepreneurial process to the concrete as they create and co-create the future from the present state with varying possible potentialities to develop into different future states. Quantum phenomena do not subject to the notion of locality that is familiar to everyday human perception. He further adds that if a quantum particle is taken to exist independently of the observer, it must be conceived as existing as a coherent potential which occupies a locality in an uncertain way (Bohm \& Fowler, 1978). Entrepreneurial event acted upon at different space-time (in a locality in a particular time) has different potential to open up, in uncertain way, to different future. The expression of the uncertainty of the potential future states can be captured in a probability distribution called the Schrodinger's wave function. The uncertainty from this can be transformed and expressed in a risk distribution (Khalil, 1997). In short, the entrepreneurial event situated in a locality at a particular time in the entrepreneurial process can only be expressed in a probability distribution from the potentialities in the entrepreneurial event. Timing, in this case, is of essence. The complexity in the chaos and indeterminism in the venture transitioning phase lie in the risks in the entrepreneurial event and how the entrepreneur's recognition and responses to that risk shape the future. A slight change in the initial condition at the entrepreneurial event can engender a radically 
different outcome. The sensitivity to the initial conditions arises when the parameters of recursive feedbacks are within a certain range (Khalil, 1997). Entrepreneurs have to rely on a probabilistic form of prediction of the future because of the way they construct the contexts of the present state based on their knowledge and imperfect information. Summarily, chaos in indeterminism (risk) differs from quantum indeterminism (uncertainty). Risk arises from imperfect information of the entrepreneurs because of their observational shortcoming, knowledge or prior experiences. Uncertainties stem from ignorance and any actions arising from an entrepreneurial event with absolute uncertainties as defined in (Knight, 1921) must be from the role of luck if the outcome turns positive.

\section{ROLE OF LUCK AND PROPITIOUS TIMING IN ENACTMENT}

The luck principle described as " an action is undetermined at a time $t$, then it's happening rather than not happening at " $t$ " would be a matter of chance or luck" and the indeterminism undermines free will and responsibility (Kane, 1999). Implicit in this, luck is therefore defined as the unexpected and therefore unpredictable component of performance (Liechti et al., 2018). According to (Liechti et al., 2018) successful entrepreneurs have persistent market timing abilities as opposed to sheer luck. The persistent market timing is referred in this paper as propitious time in enactment. When and how these entrepreneurs act determine the course and direction of the futures. In (Darke \& Freedman, 1997), their findings of locus of control and attributional models of perceived control describe luck as an external, unstable, and therefore uncontrollable causal factor- the consequence that any events thought to be determined by luck should have no implications for future outcomes. This perspective, according to (Darke \& Freedman, 1997) assumes that most, if not all, individuals maintain a rational view of luck's causal properties. The studies show that there are in fact important and reliable individual differences in terms people's views of luck. Their research concludes that good luck served as a source of positive expectations for believers, rather than being considered irrelevant and their findings suggest that people's reactions to lucky events depend substantially on their beliefs about luck (Darke \& Freedman, 1997). It is their irrational belief of the luck element contributing to their positiveness that eventually drives their actions. Furthermore, their findings also imply that it is the perceived internality and stability of events, including their deemed locus of control, rather than the particular attributions made such as skill, luck, effort, or difficulty. It is interesting to note that irrational beliefs about luck are somewhat selfserving though they can uplift the positiveness and drive actions. This irrationality is hard to be empirically determined. Beliefs in luck are unrealistically positive self-evaluations of situation (their idiosyncratic interpretation of reality), since they are specific to luck that acts in one's favour but not otherwise. Further, beliefs in good luck seemed to provide individuals with a feeling of confidence or certainty when luck was associated with the situation in some way. Social and personality psychologists have begun to reconsider whether similar biases and illusions are necessarily maladaptive. In particular (Taylor \& Brown, 1988) have argued that people are prone to a number of positive illusions that lead to unrealistically positive self- evaluations, overestimates of control, and greater optimism than is warranted by objective circumstances and this has close resemblance to their beliefs in luck. What remains to be determined is whether such beliefs can be useful or adaptive in at least some circumstances or whether they are simply liabilities or lucky for entrepreneurs. Considerable research evidence suggests that overly positive self-evaluations, exaggerated perceptions of control or mastery, and unrealistic optimism are characteristic of normal human thought (Taylor \& Brown, 1988) and particularly for entrepreneurs with such illusions or imaginations, they may engage in further productive, creative work and strategizing into the future premising on these beliefs. These strategies may succeed, in large part, because both the social-material world and cognitive-processing mechanisms impose filters on incoming information that distort it in a positive direction with a reality-distortion tendency (Eisenmann, 2013). Steve Jobs was famous for his mesmerizing "reality distortion field," through which he impelled, shaped and nudged employees, partners, and investors to go to extraordinary lengths to help fulfil his extraordinary dreams. These positive illusions may be especially useful such as the belief in luck in pushing the boundaries and extending the play of the venture (Taylor \& Brown, 1988). Those individuals who believe in luck are more likely to develop an illusion of control over events that are objectively chance determined and not naturally controllable. The belief in luck and in deciding when to act is also very closely related to the uncertainty and risk distinction.

\section{PROPITIOUS TIMING UNDER CONDITIONS OF KNIGHT'S UNCERTAINTY/ RISK}

There is an interesting parallel, at least heuristically, between the two kinds of indeterminism in physics and in Frank Knight's (Knight, F, 1921)(Mousavi \& Gigerenzer, 2014) distinction and differentiation between uncertainty and risk. Knight differentiates between the "real" doctrine of probability on one hand (with improbable determination of risk), and "ignorance" theory of probability (with probable determination of risk) on the other. The real doctrine expresses "uncertainty" in the sense that future states are not given facts and therefore situated in an "unknown mean-unknow end" quadrant/ space. See Diagram 3. Situated in the present ("now"), the entrepreneur has to decide on the mean to pursue basing on the context of socio-material network, its munificence or deficit to achieve the end.

In the pair of "unknown mean-unknown end" this is absolute Knight's uncertainty (Knight, 1921) with both means and ends being unknown; in situations of uncertainty where the agent is unable to assign probabilities to event because it is not possible to calculate the chances (Runde, 1998). It is in a state of disequilibrium with volatility. Such volatility posited within 
it, opportunities that may be hard to assign probability to success and therefore have to rely on intuition (Sadler-Smith, 2016) or in this case luck to explain their decision to act if actions are taken in the "unknown mean-unknown end" pair. Entrepreneurship presupposes calculable outcomes. Contexts are therefore crucial and specifically in the understanding of the nature of the contexts of what is known and what is unknown. At any point in the process, there is always the possibility of misfiring (judgement error) or mis-alignment between the creative efforts of entrepreneurs and what the external environment presents. Whether the opportunities are discovered, created, co-created, the essence is that the process is one of enactment (Weick \& Karl E, 1995) where it's an "incision" because it carves brackets around some portion of the flux (Weick, 2020) for actions. This study therefore describes a nexus rather than a disjunction. The nexus between experience and understanding shrinks the understanding on how to act and any actions thereof must be an intuition or on the belief of luck. In the case of bricolage and effectuation (Fisher, 2012) entrepreneurs have to rely on, combinations and the recombinants of existing local resources- "acting its way into sense". Intuition or sensemaking in the belief of luck draws this vague outline of "what-to-do-next"; calls for an evolving experience as the entrepreneurs move along the pathway. When this same intuition is described as a "non-sequential, and non-conscious information processing mode that comprises both cognitive and emotional elements, bricolage and effectuation are thus activity of improvisation, in this case with the belief of luck according the venture with positive outcomes. Improvisation also tends to be rapid non-sequential activities that can generate different pathways (Weick, 2020) at that specific point in time or in the propitious timing where outcomes arising from the actions will be deem favourable. Timing of actions therefore are the determinants of the many possible pathway development.

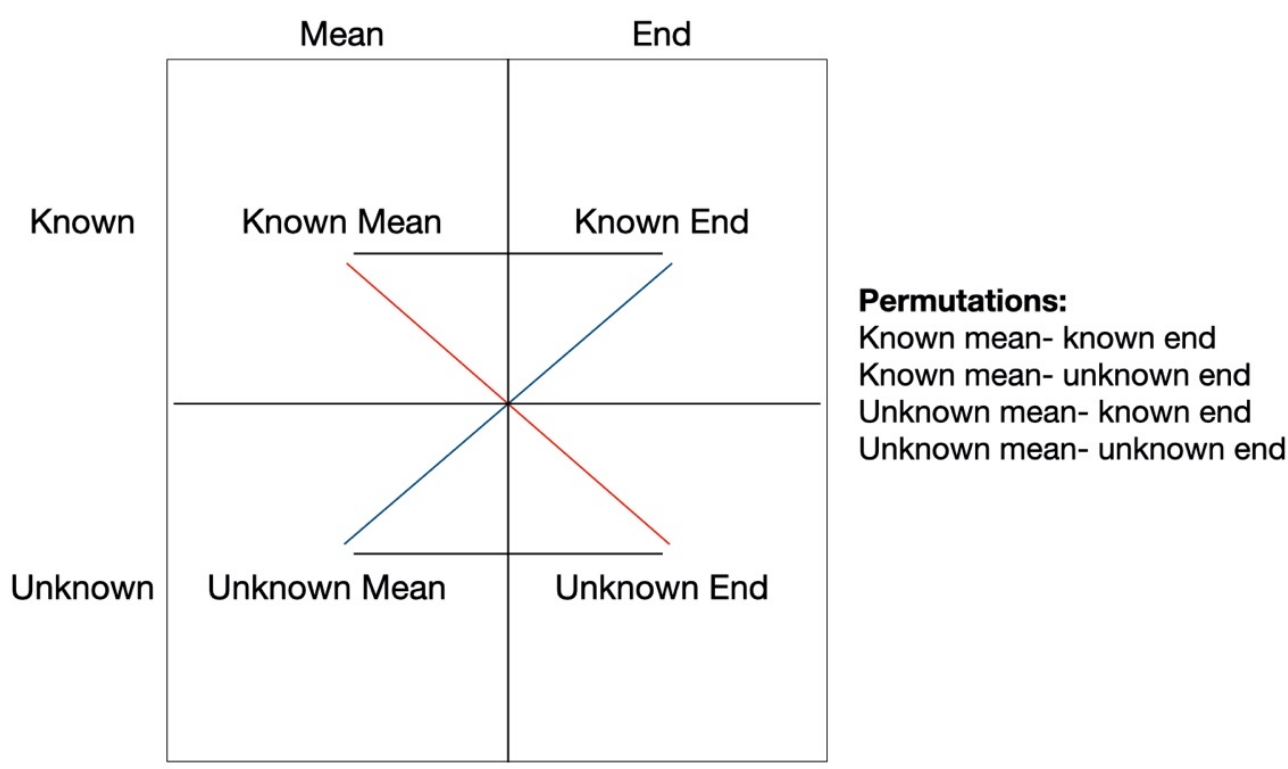

\begin{abstract}
Known mean- known end:
Known mean- unknown end: Construction/ creation from a diverse range of available known means.

Unknown mean- known end: Perceived and recognised opportunity (end), finding means to achieve.

Unknown mean- unknown end: Disequilibrium. Chaos.
\end{abstract}

Diagram 3, Mean-end framework

In contrast, the ignorance theory denotes "risk" in the sense that future states are facts in a world of certainty and can therefore be probabilistically determined. However, such facts are not fully and perfectly available to the entrepreneurs. They express limited information which makes entrepreneurs formulate only chance probability (risk) about their occurrence. In Diagram 4, it illustrates the degrees of uncertainties with levels of opportunities and risks.

Degree of Uncertainties

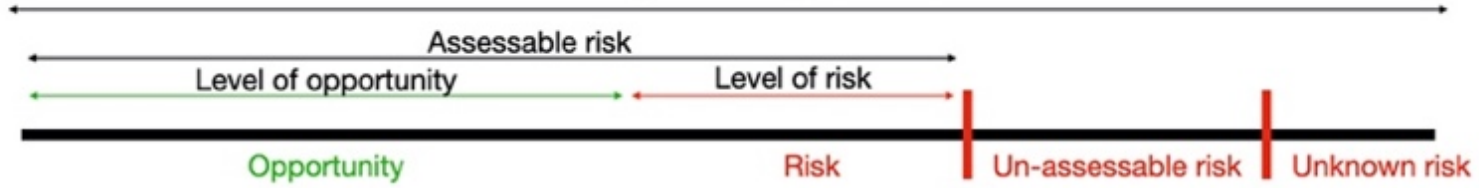

Diagram 4, Opportunity and risk and degree of uncertainties. 


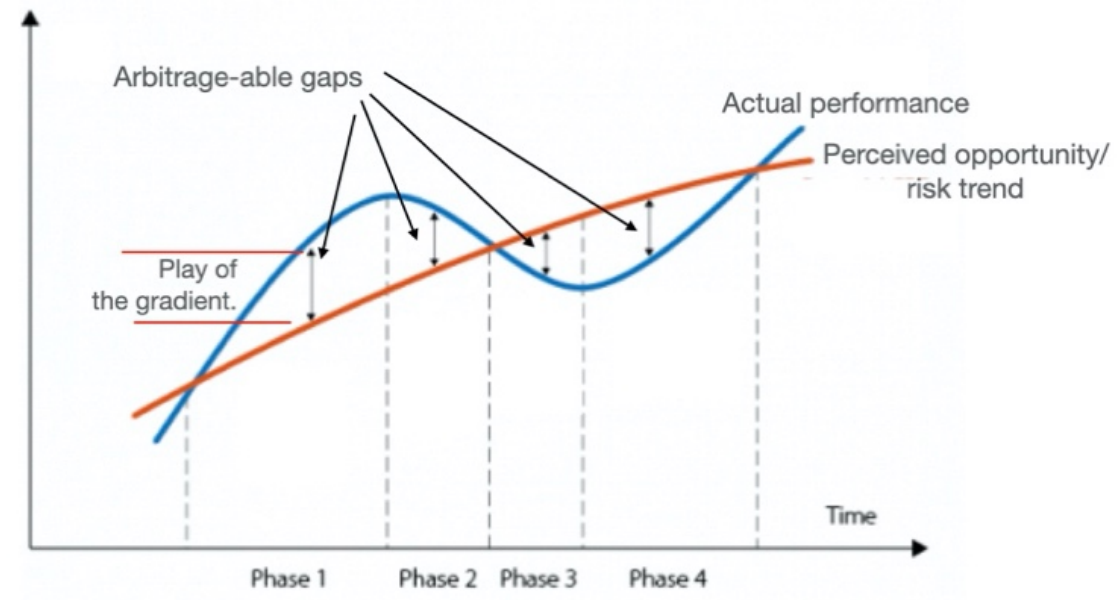

Diagram 5, Play of the gradient - arbitrage-able gaps.

Risks stem from the presence of more than one state with a non-zero probability of occurrence (Lumpkin et al., 2011). The fundamental action of the entrepreneur is to identify the best opportunities based on the risk profiles of each action arising from the opportunity exploitation and arbitrage through the play of the gradient (see Diagram 5 on the play of gradient arbitraging the gaps). Propitious timing in the enactment is necessary when the risk is bearable. The risks and opportunities existing in the space are exogenously presented. Entrepreneurs need to demonstrate dynamic adaptability and innovation in their business models to achieve survival and growth, in particular in the face of high levels of exogenous change (Schneider, 2019). The prospect of discovering an opportunity in the opportune time or propitious timing in the exploration of the opportunities with the attendant risks presuppose that the space to be explored is exogenously presented, at the opportune time and are existing, but unexplored and undiscovered. This ontological assumption is realism on the assumption that the opportunities or risks exist independent of the entrepreneur. The constructivist ontology of opportunity creation is premised on the creation of the opportunity by the entrepreneur. The model assumes that opportunity production proceeds through several stages, including conceptualization of an opportunity idea by an entrepreneur, objectification of that idea, and enactment of the opportunity into a new venture (Wood \& McKinley, 2010). However, faced with an incomplete picture of risks and opportunities in terms of the supply and/or demand or the position in space-time where these risks and opportunities are posited/ presented or created, the entrepreneur stands on these risks and opportunities to create new venture pathways (see Diagram 6 on certainty, uncertainty and risks).

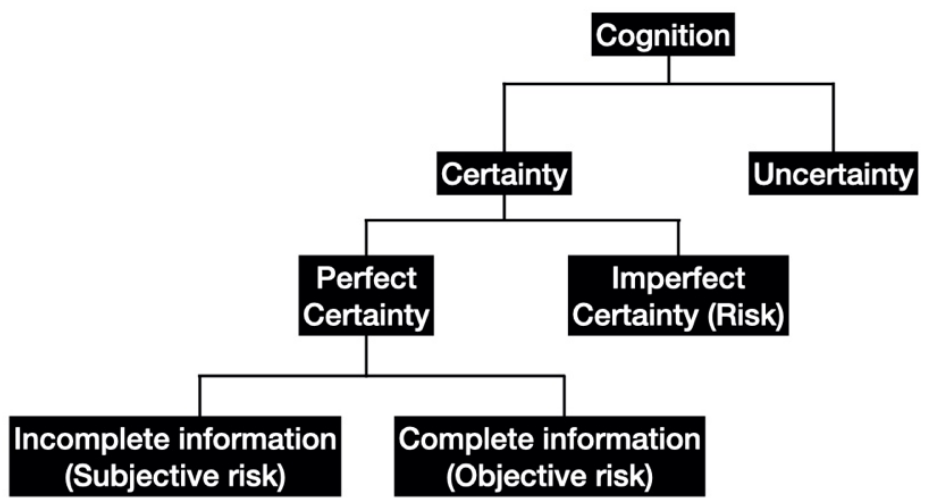

The Lexicon of Certainty. Adapted from Khalil, E. L. (1997). Chaos Theory versus Heisenberg's Uncertainty: Risk, Uncertainty and Economic Theory. The American Economist, 41(2), 27-40.

Diagram 6, Certainty, uncertainty and risks.

Again, at every set of opportunities with their attendant risks that are presented at the various times along the journey, what spur these entrepreneurs to consider actions in the various quadrants as seen in Diagram 3 "mean-end" framework? When expressing the "ontologically" non-knowable (unknown mean-unknown end), in Knightian term "absolute uncertainty", we are no longer studying the macro fluctuations but rather entrepreneurship (Khalil, 1997), in short entrepreneurial venturing . 


\section{CONCLUSION}

The belief of luck, propitiousness in the timing of actions that drives action is the core of this paper. The phenomenon of confidence or optimistic expectations pertinent to one of the many entrepreneurial events in the entrepreneurial process/ journey has to do with the anticipation of the future situated in the present "now" premising on the collective memories of prior experiences. The question is- can the future be presented as a measurable risk? The illustration of the Diagram 3 "meanend" framework, the various states of unknown in means and ends produce different decision on the pathway development which are typically non-linear. The characteristics of entrepreneurial events as described by (Bygrave, 1993) include nonlinearity, in state of discontinuity in a dynamic process, subject to change of state and involve numerous antecedent variables. Each pathway is unique.

This paper primarily examines the play of time in the entrepreneurial process and ascertain that time is of essence. Perturbations which include external shocks, triggers and stresses, the entrepreneurs' reactions and responses, by way of knowing the means or unknowing the means create varying pathways and again the timing of actions determine the success of venture. Intuition and belief of luck are explained in this paper where the entrepreneurs are situated in the blind quadrant (unknown mean-unknown end) in the mean-end framework. Optimistic prediction creates its own conditions of fulfilment, while pessimistic expectation engenders a slowdown in entrepreneurial activity. Positive expectation, or what social psychologists call "high self-efficacy". The centrality of the self-efficacy mechanism in entrepreneurship. influence thought patterns, actions and emotional arousal including the belief in luck. In (Bandura, 1982) the paper states that the higher the level of induced self-efficacy, the higher the performance accomplishments and the lower the emotional arousal. In Bandura's paper, different lines of research were reviewed, showing that the self-efficacy mechanism may have wide explanatory power. Perceived self-efficacy helps to account for such diverse phenomena as changes in coping behaviour produced by different modes of influence, level of physiological and physical stresses, achievement strivings, growth of intrinsic interest (Bandura, 1982), and including entrepreneurial pursuits. Hence, the initiation of the self-efficacy mechanism in this case arises from the internal trigger of the entrepreneurs. The influential role of perceived self-efficacy from intuition or belief in luck leads to favourable development of the entrepreneurial process.

Entrepreneurial success calls for sustained endeavour over a long time, proximal subgoals are needed to provide incentives and evidence of progress along the way and in each entrepreneurial event, the decision, at the specified time, on the responses to actions arising from the perturbations shape the entrepreneurial journey.

In conclusion, there are clearly numerous fundamental reasons, of which we have highlighted only a few of the important ones, for including time in the entrepreneurial process and the timing of actions are crucial to the outcomes of the venture. In all these, time is very much of essence in entrepreneurial venturing.

About The Author: David Leong, $P h D$ started his entrepreneurial ventures early, soon after he graduated from the National University of Singapore in 1994 with a Bachelor of Business Administration degree. He has founded various ventures from corporate finance, business consultancy, design consultancy, human resources (HR), publication and technology.

David was awarded his PhD from Charisma University in 2020 and is pursuing his Doctor of Business Administration with the University of Canberra for a double doctorate. His research is in entrepreneurship and he is venturing to define "entrepreneurial energy" as the energy field spurring entrepreneurial actions in the light of complex science and quantum science. His other research area is in the Chinese Yijing and he draws the relatedness of Yijing with modern science in particular quantum physics. 


\section{REFERENCES}

Alvarez, S. A., \& Barney, J. B. (2010). Entrepreneurship and Epistemology: The Philosophical Underpinnings of the Study of Entrepreneurial Opportunities. Academy of Management Annals, 4(1), 557-583. https://doi.org/10.5465/19416520.2010.495521

Ardichvili, A., Cardozo, R., \& Ray, S. (2003). A theory of entrepreneurial opportunity identification and development. Journal of Business Venturing, 18(1), 105-123. https://doi.org/10.1016/S0883-9026(01)00068-4

Bandura, A. (1982). Self-efficacy mechanism in human agency. American Psychologist, 37(2), 122-147. https://doi.org/10.1037/0003066X.37.2.122

Bankoff, G. (2004). Time is of the essence: disasters, vulnerability and history. International Journal of Mass Emergencies and Disasters, 22(3), 23-42.

Bird, B. J., \& West, G. P. (1998). Time and Entrepreneurship. Entrepreneurship Theory and Practice, 22(2), 5-9. https://doi.org/10.1177/104225879802200201

Bohm, D. (1973). Quantum theory as an indication of a new order in physics. B. Implicate and explicate order in physical law. Foundations of Physics, 3(2), 139-168. https://doi.org/10.1007/BF00708436

Bohm, D., \& Fowler, D. R. (1978). The Implicate Order. Process Studies, 8(2), 73-102. https://doi.org/10.5840/process19788222

Bygrave, W. D. (1993). Theory building in the entrepreneurship paradigm. Journal of Business Venturing, 8(3), $255-280$. https://doi.org/10.1016/0883-9026(93)90031-Y

Bygrave, W. D., \& Hofer, C. W. (1992). Theorizing about Entrepreneurship. Entrepreneurship Theory and Practice, 16(2), 13-22. https://doi.org/10.1177/104225879201600203

Cardon, M. S., \& Kirk, C. P. (2015). Entrepreneurial Passion as Mediator of the Self-Efficacy to Persistence Relationship. Entrepreneurship: Theory and Practice, 39(5), 1027-1050. https://doi.org/10.1111/etap.12089

Chiles, T. H., Bluedorn, A. C., \& Gupta, V. K. (2007). Beyond creative destruction and entrepreneurial discovery: A radical Austrian approach to entrepreneurship. Organization Studies, 28(4), 467-493. https://doi.org/10.1177/0170840606067996

Cope, J. (2003). Entrepreneurial Learning and Critical Reflection. Management Learning, 34(4), 429-450. https://doi.org/10.1177/1350507603039067

Dace, T. (2018). The arrow of time. Cosmos and History, 14(3), 321-333. https://doi.org/10.4006/1.3033463

Darke, P. R., \& Freedman, J. L. (1997). The belief in good luck scale. Journal of Research in Personality, 31(4), 486-511. https://doi.org/10.1006/jrpe.1997.2197

Dimov, D. (2011). Grappling With the Unbearable Elusiveness of Entrepreneurial Opportunities. Entrepreneurship: Theory and Practice, 35(1), 57-81. https://doi.org/10.1111/j.1540-6520.2010.00423.x

Eisenmann, T. R. (2013). Entrepreneurship: A Working Definition. Harvard Business Review, 1-3. https://hbr.org/2013/01/what-isentrepreneurship

Fisher, G. (2012). Effectuation, causation, and bricolage: A behavioral comparison of emerging theories in entrepreneurship research. Entrepreneurship: Theory and Practice, 36(5), 1019-1051. https://doi.org/10.1111/j.1540-6520.2012.00537.x

Gartner, W. B. (1988). “Who Is an Entrepreneur?” Is the Wrong Question. American Journal of Small Business, 12(4), 11-32. https://doi.org/10.1177/104225878801200401

Garud, R., Gehman, J., \& Giuliani, A. P. (2014). Contextualizing entrepreneurial innovation: A narrative perspective. Research Policy, 43(7), 1177-1188. https://doi.org/10.1016/j.respol.2014.04.015

Goddard, S. E. (2009). Brokering change: networks and entrepreneurs in international politics. IT, 1, 249.

Griffin, \& David Ray, E. (1986). Physics and the ultimate significance of time: Bohm, Prigogine, and process philosophy. SUNY Press.

Heckmann, L. H., Baas, J., \& Jager, T. (2010). Time is of the essence. Environmental Toxicology and Chemistry, 29(6), 1396-1398. https://doi.org/10.1002/etc.163

Ireland, R. D., \& Webb, J. W. (2009). Crossing the great divide of strategic entrepreneurship: Transitioning between exploration and exploitation. Business Horizons, 52(5), 469-479. https://doi.org/10.1016/j.bushor.2009.05.002

Jack, S., Dodd, S. D., \& Anderson, A. R. (2008). Change and the development of entrepreneurial networks over time: A processual perspective. Entrepreneurship and Regional Development, 20(2), 125-159. https://doi.org/10.1080/08985620701645027

Kane, R. (1999). Responsibility, Luck, and Chance: Reflections on Free Will and Indeterminism. The Journal of Philosophy, $96(5), 217$. https://doi.org/10.2307/2564666

Khalil, E. L. (1997). Chaos Theory Versus Heisenberg's Uncertainty: Risk, Uncertainty and Economic Theory. The American Economist, 41(2), 27-40. https://doi.org/10.1177/056943459704100204

Kirzner, I, . (1997). Entrepreneurial discovery and the competitive market process. An Austrian Approach. Journal of Economic Literature, 35: $60-85$.

Kirzner, I. M. (1973). Competition and Entrepreneurship. University of Chicago Press.

Kirzner, Israel M. (1999). Creativity and/or alertness: A reconsideration of the schumpeterian entrepreneur. In Review of Austrian Economics (Vol. 11, Issues 1-2). https://doi.org/10.1023/a:1007719905868

Knight, F, . (1921). Risk, uncertainty and profit. . New York: Augustus Kelley.

Kuckertz, A. (2019). Let's take the entrepreneurial ecosystem metaphor seriously! Journal of Business Venturing Insights, 11(April), e00124. https://doi.org/10.1016/j.jbvi.2019.e00124

Leong, D. (2020). Entrepreneurial Energy and Opportunities Existing in Space. Journal of Entrepreneurship, Business and Economics, 8(2), 196-218. http://scientificia.com/index.php/JEBE/article/view/144

Leong, D. (2021). Entrepreneurial Energy in a Far-From-Equilibrium Opportunity Driving Entrepreneurial Actions. Journal of Entrepreneurship, Business and Economics, 9(1), 1-31. http://www.scientificia.com/index.php/JEBE/article/view/143

Lichtenstein, B. B., Dooley, K. J., \& Lumpkin, G. T. (2006). Measuring emergence in the dynamics of new venture creation. Journal of Business Venturing, 21(2), 153-175. https://doi.org/10.1016/j.jbusvent.2005.04.002

Liechti, D., Loderer, C. F., \& Peyer, U. (2018). Luck and Entrepreneurial Success. SSRN Electronic Journal. https://doi.org/10.2139/ssrn.2476839

Lumpkin, G. T., Steier, L., \& Wright, M. (2011). Risk and Rationality in Entrepreneurial Process. Strategic Entrepreneurship Journal, 
306(November), 285-306. https://doi.org/10.1002/sej

Messier, C., \& Puettmann, K. J. (2011). Forests as complex adaptive systems: implications for forest management and modelling. L'Italia Forestale e Montana, 249-258. https://doi.org/10.4129/ifm.2011.3.11

Mises, L. Von. (1949). Human action: A treatise on economics (4th revised ed.). In San Francisco: Fox \& Wilkes.

Morris, M. H., Kuratko, D. F., Schindehutte, M., \& Spivack, A. J. (2012). Framing the entrepreneurial experience. Entrepreneurship: Theory and Practice, 36(1), 11-40. https://doi.org/10.1111/j.1540-6520.2011.00471.x

Mousavi, S., \& Gigerenzer, G. (2014). Risk, uncertainty, and heuristics. Journal of Business Research, 67(8), 1671-1678. https://doi.org/10.1016/j.jbusres.2014.02.013

Nutt, P., \& R., B. (1997). Crafting vision. Journal of Management Inquiry, 6(4), 308-328.

Pitelis, C. (2012). Clusters, entrepreneurial ecosystem co-creation, and appropriability: A conceptual framework. Industrial and Corporate Change, 21(6), 1359-1388. https://doi.org/10.1093/icc/dts008

Runde, J. (1998). Clarifying Frank Knight's discussion of the meaning of risk and uncertainty. Cambridge Journal of Economics, 22(5), 539-546. http://www.jstor.org/stable/23600452

Russell, R., \& Faulkner, B. (2004). Entrepreneurship, Chaos and the Tourism Area Lifecycle. Annals of Tourism Research, 31(3), 556-579. https://doi.org/10.1016/j.annals.2004.01.008

Sadler-Smith, E. (2016). The role of intuition in entrepreneurship and business venturing decisions. European Journal of Work and Organizational Psychology, 25(2), 212-225. https://doi.org/10.1080/1359432X.2015.1029046

Sarason, Y., Dean, T., \& Dillard, J. F. (2006). Entrepreneurship as the nexus of individual and opportunity: A structuration view. Journal of Business Venturing, 21(3), 286-305. https://doi.org/10.1016/j.jbusvent.2005.02.007

Sarasvathy, S. D. (2001). Causation and Effectuation: Toward a Theoretical Shift from. Academy of Management Review, 26(2), $243-263$.

Sarasvathy, S. D. (2003). Entrepreneurship as a science of the artificial. Journal of Economic Psychology, 24(2), 203-220. https://doi.org/10.1016/S0167-4870(02)00203-9

Schneider, S. (2019). How to approach business model innovation: the role of opportunities in times of (no) exogenous change. $R \& D$ Management, 49(4), 399-420. https://doi.org/10.1111/radm.12302

Schumpeter, J. A. . (1934). The theory of economic development. . Cambridge, MA: Harvard University Press.

Shane, S. (2003). A general theory of entrepreneurship: The individual-opportunity nexus. A General Theory Of Entrepreneurship: The Individual-Opportunity Nexus, 1-327. https://doi.org/10.4337/9781781007990

Shepherd, D. A., Douglas, E. J., \& Shanley, M. (2000). New venture survival: Ignorance, external shocks and risk reduction strategies. Journal of Business Venturing, 15(5-6), 393-410. https://doi.org/10.1016/S0883-9026(98)00032-9

Taylor, S. E., \& Brown, J. D. (1988). Illusion and well-being: a social psychological perspective on mental health. Psychological Bulletin, 103(2), 193.

Valliere, D. (2015). An Effectuation Measure of Entrepreneurial Intent. Procedia - Social and Behavioral Sciences, 169(August 2014), 131142. https://doi.org/10.1016/j.sbspro.2015.01.294

Warner, B., \& Simon, H. A. (1969). The Sciences of the Artificial. In or (Vol. 20, Issue 4). https://doi.org/10.2307/3008782

Weick, ., \& Karl E, . (1995). Sensemaking in organizations. . Thousand Oaks, CA: SAGE.

Weick, ., Karl E, ., Sutcliffe, K. M, ., \& Obstfeld, D, . (2005). Organizing and the Process of Sensemaking. . Organization Science, 16(4), 409421.

Weick, K. E. (2020). Sensemaking, Organizing, and Surpassing: A Handoff*. Journal of Management Studies, 57(7), 1420-1431. https://doi.org/10.1111/joms.12617

Wood, M. S., \& McKinley, W. (2010). The production of entrepreneurial opportunity: a constructivist perspective. Strategic Entrepreneurship Journal, 4(1), 66-84. https://doi.org/10.1002/sej.83 